\title{
EDITORIAL
}

\section{The vapes of wrath: advocating to protect children from electronic nicotine systems in the age of flavored vapes}

\author{
Pediatric Research (2020) 87:972-975; https://doi.org/10.1038/s41390- \\ 020-0872-z
}

In this issue, Liu et al. posit a novel comorbidity in neonates born to women prenatally exposed to second-hand smoke. ${ }^{1}$ The authors found an approximate $10 \%$ difference in telomere length in infants born to mothers with second-hand smoke exposure and intriguingly suggest possible gender differences in the in utero susceptibility to maternal prenatal second-hand smoke exposure. The pediatric comorbidities associated with second-hand smoke exposure are well documented and include Sudden Infant Death Syndrome, wheezing, lower respiratory tract infection, pneumonia, bronchiolitis and otitis media. ${ }^{2-4}$ Infant urine cotinine levels-a nicotine metabolite-are inversely related to infant lung function. ${ }^{5}$ Second-hand smoke exposure is also a significant source of increased healthcare utilization and a risk factor for decreased school attendance. Exposed children wct 2utilize the emergency and urgent care facilities and are hospitalized more frequently than those unexposed to second-hand smoke. ${ }^{3,4,6}$ Fortunately, decades of public health messaging and increased understanding of these effects have contributed to reduced rates of combustible tobacco use in both women of reproductive age and pregnant women. ${ }^{7-10}$

In sharp contrast to this decline however, the use of electronic cigarettes and nicotine delivery systems has exponentially increased in all age groups. ${ }^{11,12}$ Rates of e-cigarette use in adults of reproductive age doubled to $4.2 \%$ from 2012 to 2014 . $^{7}$ More than $10 \%$ of these adults vape exclusively, having never used combustible tobacco. Yet youth vaping and e-cigarette use may be a pathway to traditional cigarette smoking, particularly in previously low-risk children. ${ }^{13}$ Exclusive e-cigarette users are at high risk of beginning combustible cigarette use within 2 years of initiating vaping. ${ }^{14,15}$ Currently, $27.5 \%$ of United States youth report using an electronic cigarette within the past 30 days and rates of use in children have increased by over $100 \%$ in the past 2 years. ${ }^{16}$ Though popularly conceived as a safer alternative to combustible cigarettes, these products contain toxicants such as formaldehyde, propylene glycol, acetylaldehyde, vegetable glycerin and acrolein. ${ }^{17}$ These substances also have the potential to cause oxidative stress, promote inflammation, induce mutagenesis and may be associated with increased cancer risk. ${ }^{18}$ Further, the outcome of prenatal vaping on birth outcomes is unknown. The potential for youth use to fuel a burgeoning increase in use of these products in women of reproductive age within several years, accompanied by the known association of vaping with combustible tobacco use, is significant.

Across the spectrum of nicotine delivery systems, flavored vape products are extremely appealing to youth. Among current tobacco users, $80 \%$ of youth and $73 \%$ of adults $18-24$ years use flavored products and $60 \%$ of specifically cite flavors as a reason for continued use. ${ }^{19}$ Many teen and young adults are unaware these products contain nicotine. ${ }^{20}$ Based on these findings, the United States government has engaged in several actions aimed at reducing youth electronic cigarette use, specifically targeting flavored products. In 2016, the FDA Center for Tobacco Products asserted regulatory authority over electronic nicotine delivery systems, and restricted their sale to anyone under 18 years of age. $^{21}$ The agency has issued warning letters and leveled civil complaints to retailers who sell to minors and has prohibited the distribution of free tobacco products samples. ${ }^{22}$ The agency also required, as of June 2019, for these products to state they contain nicotine and to have the ingredients listed. ${ }^{21}$

However, the most effective strategy to restrict sale of flavored vape products and curb youth use may be via use of the FDA's requirement that these products undergo FDA approval prior to sale. In July of 2019, a US Federal Court ordered electronic cigarette manufacturers to submit applications for FDA premarket review by May of $2020 .^{23}$ The FDA would then have the ability to limit or prohibit sale of these products if the agency feels they do not have a legitimate public health role. Such a public health role may include the use of flavored tobacco products to reduce the use of combustible cigarettes in adults who currently smoke. ${ }^{21,24}$ Yet, even if flavored vape devices are shown to provide a benefit to current smokers, the FDA could still substantially restrict use if the agency deems the threat of youth tobacco initiation outweighs potential benefits to current adult smokers. However, given the politicization of federal regulation in the current administration, it remains unclear what level of permissiveness the agency will allow in evaluating these products, including to what extent and scrutiny industry-sponsored research will be reviewed. Hence there is little assurance FDA actions will be comprehensive. Like state laws and Presidential executive actions, these measures are limited in scope and finite.

In the absence of a rapid, comprehensive federal response, states and municipalities have been regulating tobacco flavors locally. For example, to address the vaping epidemic, California's governor recently signed an executive order that earmarks funds for education and increases enforcement of underage sales. ${ }^{25}$ Though San Francisco was the first major city to prohibit the sale of flavored tobacco products, several states and New York City have followed-motivated by over 1200 vape-related hospitalizations nationwide, the rapid uptake of these products by children and concerns of child-health advocates, including pediatricians, parents and teachers (Table 1). ${ }^{26-34}$ Preliminary data have shown prohibiting the sale of flavored vape products may be effective in reducing teen vaping. In comparing two local communities, Kingsley et al. ${ }^{35}$ demonstrated a flavor ban reduced current use of both flavored and unflavored tobacco products in children within 6 months after implementation. This result is promising; however, flavor prohibitions in states are too new to determine their longterm and sustained impact on youth vaping beyond the 6-month study period. These policies will provide a natural long-term experiment for public health researchers to evaluate if sales prohibitions in flavored nicotine, as a policy tool, reduce teen use, and if so, to what extent. However, the immediacy of this threat to child health, in conjunction with the meteoric rise in the use of these products, necessitates a "Do No Harm" approach which underlies the need for flavor prohibitions. Similar studies provided data illustrating the compelling role of "Tobacco 21 " laws-which 
Table 1. Selected United States prohibitions on the sale of flavored vaping/electronic cigarette products (as of fall 2019).

\begin{tabular}{|c|c|c|}
\hline State & Scope of prohibition & Duration (months) \\
\hline Massachusetts 29,30 & Ban on all vape sales, including marijuana permanent prohibition passed Legislature, Nov. 2019 & 4 \\
\hline Washington $^{32}$ & Ban on flavored vape products, including nicotine and marijuana & 4 \\
\hline Oregon $^{33}$ & Ban on flavored nicotine and cannabis electronic cigarettes, excludes $100 \%$ marijuana terpenes & 6 \\
\hline Montana ${ }^{34}$ & Ban on all vape products Containing Nicotine or Marijuana & 4 \\
\hline
\end{tabular}

raise the age to purchase tobacco to 21 years-on reducing teenage smoking caused long-term delays in tobacco control efforts, and in the interim, allowing more children entry into nicotine addiction. ${ }^{36,37}$

The President has also considered a variety of actions, from a complete ban on flavored products, to restricting sale of flavored products exclusive to specific retail establishments to only allowing continued sale of mint and menthol products. ${ }^{38-40}$ In January 2020, the President released a limited ban on flavored vape products with a narrow FDA regulation that prohibits the sale of flavored cartridge-based vape products. Yet this directive contains significant, if not gaping, exemptions. Open-tank vaping systems are excluded from the flavor rule, and disposable vaping systems (i.e. FOGG, PUFF and MOJO) are in a regulatory gray area. Furthermore, this ban maintains protection for many mint and all menthol products. ${ }^{41}$ The inclusion of these specific flavors in a ban is an essential component of teen vape prevention. Mint is second only to fruit flavors in popularity among teens who vape and menthol anesthetic qualities quall the airway irritation created by inhaling tobacco or vape fluids, and allow for improving delivery of addictive nicotine to the distal respiratory tract. ${ }^{16}$ The 2009 Family Smoking Prevention and Tobacco Control Act granted special exemption to menthol in its prohibition of flavoring for traditional cigarettes. Hence many local laws on vape flavors have similarly excluded menthol, fearing legal action by tobacco retailers. However, it must be noted that unilateral Presidential action would not be enduring, and subject to immediate invalidation with a change in Presidential administration.

Given the slow pace of FDA regulation, which has failed to produce graphic tobacco warnings on combustible cigarettes after more than a decade after being required by Congress due to litigation, federal legislative action may be the only comprehensive means of prohibiting vape flavors nationwide. ${ }^{42}$ This would prevent piece-meal regulation and deficient White House regulations from prevailing. The "Reversing the Youth Tobacco Epidemic Act", first introduced in April of 2019, would demonstrate a strong federal commitment to preventing youth access to flavored tobacco products. ${ }^{43}$ The bill cosponsored by 114 members of Congress, as of this writing, would eliminate flavorings and remote sales of tobacco products, and end the legal protection and favoritism bestowed on mint and menthol.

The bill is not without critics. Provaping advocacy groups argue stricter regulations on sales to minors, such as "Tobacco 21", and punitively high financial fines for vape owners who sell to children will be sufficient to curb youth vaping use and still allow for local business to sell these products. A ban on any sale of these products should not be enacted until stricter enforcement of existing rules preventing sale to children is more widely implemented and rigorously evaluated. ${ }^{44}$
Critics of the proposal claim removing flavors from vape products will promote more combustible tobacco use and remove a product that facilitates smoking cessation. ${ }^{43-46}$ There is some evidence that flavorings may help reduce the amount of cigarettes used by adult smokers in the short term. ${ }^{47}$ Examining adults aged $21-35$ years, Tseng et al. ${ }^{48}$ conducted a blinded randomized trial of nicotine versus placebo e-cigarettes and found that after 3 weeks, those in the intervention arm of the trial smoked less. However, as the researchers acknowledge the duration of follow-up ( 3 weeks) was short and those enrolled in the placebo arm of the study, using flavored e-cigarettes that lack nicotine still demonstrated a significant, almost $50 \%$ reduction in cigarettes smoked per day, indicating a strong placebo effect and suggesting flavored products need not contain nicotine to impact cessation. ${ }^{48}$ Hence, as a cessation aid, electronic nicotine flavorings are unapproved by the Food and Drug Administration and unendorsed by the United States Preventive Services Task Force. ${ }^{49-52}$ Rigorous long-term studies to determine the role of vaping in adult smoking cessation in the United States are needed. If convincing evidence for a role in smoking cessation is found, these products (like nicotine patches and gums when first introduced) should initially only be available by prescription to ensure they are coordinated with medical supervision.

Therefore, allowing the sale of flavored vape products under the rationale of assisting current adult smokers is based on false premises. It also fails to account for the unique role flavors play in beginning the cycle of vape use in children. Among children, greater than $95 \%$ begin nicotine use with a flavored product and flavors are a key factor contributing to persisting vape use..$^{53,54}$ Further, teens who use these products are twice as likely to graduate to long-term combustible tobacco and up to three times more likely to use marijuana. ${ }^{14,55,56}$ The balance of public health harm resulting from a generation of potential, sustained nicotine addiction beginning in childhood clearly outweighs any, as yet, unproven benefit to adult combustible tobacco smokers.

The path toward advancing the "Reversing the Youth Tobacco Epidemic Act" is challenging. Though the measure is technically bipartisan, as of February 10, 2020, 113 of 114 cosponsors are from one US political party. As of February 28, 2020, the House of Representatives passed the legislation by a close vote of 213 to 195. Broader understanding of the role of flavorings in facilitating youth vaping by policy makers is needed as this bill moves on to the U.S. Senate. Pediatricians, who are on the front line of this epidemic, are ideal advocates to educate legislators about the inherent dangers of using these products and to provide a medical narrative of the widespread use of these products by children. We must sound a louder alarm on the impact of these devices in the children we care for, and strongly work to protect 50 years of tobacco control efforts. 


\section{AUTHOR CONTRIBUTIONS}

All authors made substantial contributions in analyzing data, drafting the manuscript, and providing critical revisions. All authors approve this final version of the manuscript.

\section{ADDITIONAL INFORMATION}

Competing interests: The authors declare no competing interests.

Publisher's note Springer Nature remains neutral with regard to jurisdictional claims in published maps and institutional affiliations.

Shetal I. Shah ${ }^{1}$, Joyce R. Javier ${ }^{2}$ and Heather L. Brumberg ${ }^{1}$ ${ }^{1}$ Maria Fareri Children's Hospital at Westchester Medical Center, New York Medical College, New York, NY, USA and ${ }^{2}$ Division of General Pediatrics, Children's Hospital Los Angeles, Keck School of Medicine, University of Southern California, Los Angeles, CA, USA Correspondence: Joyce R. Javier (jojavier@chla.usc.edu)

\section{REFERENCES}

1. Liu, B. et al. Prenatal second-hand smoke exposure and newborn telomere length. Pediatr. Res. (2019). https://doi.org/10.1038/s41390-019-0594-2.

2. Shah, S. Smoking cessation counseling and PPSV 23-valent pneumococcal polysaccharide vaccine administration parents of neonatal intensive care unit (NICU)-admitted infants: a life-changing opportunity. J. Neonatal-Perinat. Med. 4, 263-267 (2011).

3. Best, D. American Academy of Pediatrics: Technical report-Secondhand and prenatal tobacco exposure. Pediatrics 124, e1017-e1044 (2009).

4. Farber, H. J., Groner, J., Walley, S. \& Nelson, K. Protecting children from tobacco, nicotine and tobacco smoke. Pediatrics 136, e1439-e1467 (2015).

5. Moshammer, H. et al. Parental smoking and lung function in children: an international study. Am. J. Respir. Crit. Care Med. 173, 1255-1263 (2006).

6. Merianos, A., Stough, C. O., Nabors, L. A. \& Mahabee-Gittens, E. Tobacco smoke exposure and health-care utilization among children in the United States. Am. J. Health Promot. 32(Jan), 123-130 (2018).

7. U.S. Department of Health and Human Services. E-Cigarette Use Among Youth and Young Adults. A Report of the Surgeon General (U.S. Department of Health and Human Services, Centers for Disease Control and Prevention, National Center for Chronic Disease Prevention and Health Promotion, Office on Smoking and Health, Atlanta, GA, 2016).

8. Wakefield, M. A., Loken, B. \& Hornik, R. C. Use of mass media campaigns to change health behavior. Lancet 376(Oct), 1261-1271 (2010).

9. Wakefield, M. A. et al. Impact of tobacco control policies and mass media campaigns on monthly adult smoking prevalence. Am. J. Public Health 98, 1443-1450 (2008).

10. Villanti, A. C., Curry, L. E., Richardson, A., Vallone, D. M. \& Holtgrave, D. R. Analaysis of media campaign promoting smoking cessation suggests it was cost-effective in prompting quit attempts. Health Aff. 31, 2708-2716 (2012).

11. Jenssen, B. P. \& Wilson, K. M. What is new in electronic-cigarette research? Curr. Opin. Pediatr. 13, 262-266 (2019).

12. Gentzke, A. S. et al. Vital signs: tobacco product use among middle and high school students-United States, 2011-2018. MMWR Morb. Mortal. Wkly. Rep. 68, 1-8 (2019).

13. Primack, B. A., Soneji, S., Stoolmiller, M., Fine, M. J. \& Sargent, J. D. Progression to traditional cigarette smoking after electronic cigarette use among US adolescents and young adults. JAMA Pediatr. 169(Nov), 1018-1023 (2015).

14. Bold, K. W. et al. Trajectories of e-cigarette and conventional cigarette use among youth. Pediatrics 141, e2017-e1832 (2018).

15. Leventhal, A. M. et al. Association of electronic cigarette use with initiation of combustible tobacco product smoking in early adolescence. JAMA 314(Aug), 700-707 (2015).

16. Cullen, K. A. et al. E-cigarette use among youth in the United States, 2019. JAMA. https://doi.org/10.1001/jama.2019.18387 (2019).

17. Eaton, D. L., Kwan, L. Y., Stratton, K. (eds) National Academies of Sciences, Engineering, and Medicine; Health and Medicine Division; Board on Population Health and Public Health Practice; Committee on the Review of the Health Effects of Electronic Nicotine Delivery Systems. Public health consequences of E-cigarettes (National Academies Press (US), Washington, DC, 2018).

18. Kaur, G., Muthumalage, T. \& Rahman, I. Mechanisms of toxicity and biomarkers of flavoring and flavor enhancing chemicals in emerging tobacco and non-tobacco products. Toxicol. Lett. 288(May), 143-155 (2018).
19. Kingsley, M. et al. Short-term impact of a flavored tobacco restriction: changes in youth tobacco use in a Massachusetts community. Am. J. Prev. Med. 57, 741-748 (2019).

20. Boykan, R. et al. Self-reported use of tobacco, e-cigarettes, and marijuana versus urinary biomakers. Pediatrics 143, e2018-e3531 (2019).

21. Sharpless, N. How is the FDA regulating e-cigarettes? United States Food and Drug Administration, FDA Voices: perspectives from FDA leadership and experts. https://www.fda.gov/news-events/fda-voices-perspectives-fda-leadership-andexperts/how-fda-regulating-e-cigarettes (2019).

22. United States Food and Drug Administration. Compliance actions and activities, warning letters. https://www.fda.gov/inspections-compliance-enforcement-andcriminal-investigations/compliance-actions-and-activities/warning-letters (2019).

23. Glantz, S. A. Federal courts sets 10-month deadline for e-cigarette makers to apply to FDA to keep products on the market. University of California, San Francisco Center for Tobacco Control Research and Education. https://tobacco. ucsf.edu/federal-court-sets-10-month-deadline-e-cigarette-makers-apply-fdakeep-products-market (2019).

24. United States Food and Drug Administration. Modifications to compliance policy for certain deemed tobacco products. https://www.fda.gov/regulatory-information/ search-fda-guidance-documents/modifications-compliance-policy-certain-deemedtobacco-products (2019).

25. Executive Department, State of California. Executive Order N-18-19. https://www. gov.ca.gov/wp-content/uploads/2019/09/9.16.19-EO-N-18-19.pdf (2019).

26. McGinley, L. Michigan becomes first state to ban flavored e-cigarettes. Washington Post, 9/4/19. https://www.washingtonpost.com/health/michiganbecomes-first-state-to-ban-flavored-e-cigarettes/2019/09/03/34f234c6-ce4c11e9-8c1c-7c8ee785b855_story.html?noredirect=on (2019).

27. Governor Cuomo announces New York State implements first-in-the-nation ban on flavored e-cigarettes. https://www.governor.ny.gov/news/governor-cuomoannounces-new-york-state-implements-first-nation-ban-flavored-e-cigarettes (2019).

28. Mays, J. C. \& Goodman, J. D. After deaths, ban on flavored vapes to be passed by New York City. New York Times, 11-21-19. https://www.nytimes.com/2019/11/21/ nyregion/vaping-ban-nyc.html (2019).

29. Knowles, H. Massachusetts to ban sale of all vaping products for 4 months in toughest state crackdown. Washington Post, 9/24/19. https://www.washingtonpost. com/health/2019/09/24/massachusetts-ban-all-vaping-product-sales-monthstoughest-state-crackdown/ (2019).

30. Johnson, M. Massachusetts lawmakers pass flavored tobacco, vaping products ban. The Hill, 11-21-19. https://thehill.com/policy/healthcare/state-issues/471512massachusetts-lawmakers-pass-flavored-tobacco-vaping-products (2019).

31. Reynolds, M. Temporary ban on flavored vaping products takes effect in RI. Providence Journal, 10/4/19. https://www.providencejournal.com/news/ 20191004/temporary-ban-on-flavored-vaping-products-takes-effect-in-ri (2019).

32. Howard, J. \& Boyette C. Washington State has banned the sale of flavored vaping products. CNN Health, 10/10/19. https://www.cnn.com/2019/10/10/health/flavorede-cigarette-ban-washington-thursday-bn/index.html (2019).

33. Flaccus, G. Oregon approves six-month ban on flavored vape products. Associated Press, 10/11/19. https://apnews.com/1167ff6b9de84ffdb82e82b3640a0832 (2019).

34. Drake, P. Amid rising deaths and illnesses, Montana temporarily bans flavored ecigarettes. USA Today, 10/8/19. https://www.usatoday.com/story/news/health/ 2019/10/08/amid-vaping-deaths-montana-bans-flavored-e-cigarettes-120-days/ 3911425002/ (2019).

35. Kingsley, M. et al. Short-term impact of a flavored tobacco restriction: changes in youth tobacco use in a Massachusetts community. Am. J. Prev. Med. https://doi. org/10.1016/j.amepre.2019.07.024 (2019).

36. Kessel Schneider, S., Buka, S. L., Dash, K., Winickoff, J. P. \& O'Donnell, L. Community reductions in youth smoking after raising the minimum tobacco sales age to 21. Tob. Control 25, 355-359 (2016).

37. Winickoff, J. P. Testimony Before the United States House of Representatives Committee on Oversight and Reform Subcommittee on Economic and Consumer Policy (July 2019).

38. Bowden, J. Trump reversed course on flavored e-cigarette ban over fear of job losses: report. The Hill, 11/17/19. https://thehill.com/policy/healthcare/470866trump-reversed-course-on-flavored-e-cigarette-ban-over-fear-of-job-losses (2019).

39. Klar, R. Flavored e-cigarette ban stalls in White House: report. The Hill, 11/18/19. https://thehill.com/homenews/administration/470872-flavored-e-cigarette-banstalls-in-white-house-report (2019).

40. Subcommittee Chairman Krishnamoorthi seeks answers after news that President Trump may abandon e-cigarette flavor ban. https://oversight.house.gov/news/ press-releases/subcommittee-chairman-krishnamoorthi-seeks-answers-afternews-that-president (2019).

41. Weixel, N. Trump administration declares ban on mint, fruit flavored vaping products. The Hill, 1/2/20. https://thehill.com/policy/healthcare/476542-trumpadministration-declares-ban-on-mint-fruit-flavored-vaping-products (2020). 
42. United States Food and Drug Administration. Family Smoking Prevention and Tobacco Control Act-an overview. https://www.fda.gov/tobacco-products/rulesregulations-and-guidance/family-smoking-prevention-and-tobacco-control-actoverview (2019).

43. Reversing the Youth Tobacco Epidemic Act. https://www.congress.gov/116/bills/ hr2339/BILLS-116hr2339ih.pdf (2019).

44. United States Food and Drug Administration. Eliminating youth electronic cigarette and other tobacco product use: the role for drug therapies. Part 15 Public Hearing. 1/18/19. https://www.fda.gov/media/120342/download (2019).

45. Polosa, R., Caponnetta, P., Maglia, M., Marjaria, J. B. \& Russo, C. Success rates with nicotine personal vaporizers: a prospective 6-month pilot study of smokers not intending to quit. BMC Public Health 14(Nov), 1159 (2014).

46. Adriaens, K., Van Gucht, D., Declerck, P. \& Baeyens, F. Effectiveness of the electronic cigarette: an eight-week Flemish study with six-month follow-up on smoking rduction, craving and experienced benefits and complaints. Int. J. Environ. Res. Public Health 11(Oct), 11220-11248 (2014).

47. Hajek, P. et al. A randomized trial of e-cigarettes versus nicotine-replacement therapy. N. Engl. J. Med. 380(Feb), 629-637 (2019).

48. Tseng, T. et al. A randomised controlled trial comparing the effect of nicotine versus placebo electronic cigarettes on smoking reduction among young adult smokers. Nicotine Tob. Res. 18, 1937-1943 (2016).
49. Section on Tobacco Control. Electronic Nicotine Delivery Systems. Am. Acad. Pediatrics Sect. Tob. Control Policy Statement 136, 1018-1026 (2015).

50. Malas, M. et al. Electronic cigarettes for smoking cessation: a systematic review. Nicotine Tob. Res. 18, 1926-1936 (2016).

51. McRobbie, H. et al. Electronic cigarettes for smoking cessation. Cochrane Database Syst. Rev. CD010216 (2014).

52. United States Preventive Services Task Force Final Recommendation Statement. Tobacco smoking cessation in adults, including pregnant women: behavioral and pharmacotherapy interventions. https://www.uspreventiveservicestaskforce.org/ Page/Document/RecommendationStatementFinal/tobacco-use-in-adults-andpregnant-women-counseling-and-interventions1 (2019).

53. Kong, G., Morean, M. E., Cavalle, D. A., Camenga, D. R. \& Krishnan-Sarin, S. Reasons for electronic cigarette experimentation and discontinuation among adolescents and young adults. Nicotine Tob. Res. 17, 847-854 (2015).

54. Harrell, M. B. et al. Flavored e-cigarette use: characterizing youth, young adults and adult users. Prev. Med. Rep. 5, 33-40 (2017).

55. Chaffee, B. W., Watkins, S. L. \& Glantz, S. A. Electronic cigarette use and progression from experimentation to established smoking. Pediatrics 141, e20173594 (2018).

56. Dai, H., Catley, D., Richter, K. P., Goggin, K. \& Ellerbeck, E. F. Electronic cigarettes and future marijuana use: a longitudinal survey. Pediatrics 141, e20173787 (2018). 